IJOPM

41,13

152

Received 4 June 2021

Revised 10 September 2021 1 October 2021

Accepted 1 October 2021

\section{An attention-based view of supply disruption risk management: balancing biased attentional processing for improved resilience in the COVID-19 context}

\author{
Harri Lorentz \\ Turku School of Economics, University of Turku, Turku, Finland \\ Sini Laari \\ Department of Marketing and International Business, University of Turku, \\ Turku, Finland \\ Joanne Meehan \\ Management School, University of Liverpool, Liverpool, UK \\ Michael Eßig \\ Purchasing and Supply Management, Bundeswehr University Munich, \\ Neubiberg, Germany, and \\ Michael Henke \\ Enterprise Logistics TU Dortmund, Dortmund, Germany and \\ Fraunhofer Institute of Material Flow and Logistics IML, Dortmund, Germany
}

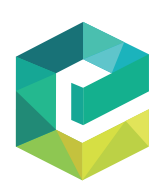

International Journal of Operations \& Production Management Vol. 41 No. 13, 2021 pp. 152-177 Emerald Publishing Limited 0144-3577

DOI 10.1108/IJOPM-06-2021-0381

\begin{abstract}
Purpose - In the context of the COVID-19 pandemic, this study investigates a variety of approaches to supply disruption risk management for achieving effective responses for resilience at the supply management subunit level (e.g. category of items). Drawing on the attention-based view of the firm, the authors model the attentional antecedents of supply resilience as (1) attentional perspectives and (2) attentional selection. Attentional perspectives focus on either supply risk sources or supply network recoverability, and both are hypothesised to have a direct positive association with supply resilience. Attentional selection is top down or bottom up when it comes to disruption detection, and these are hypothesised to moderate the association between disruption risk management perspectives and resilience.

Design/methodology/approach - Conducted at the early phases of the COVID-19 pandemic, this study employs a hierarchical regression analysis on a multicountry survey of 190 procurement professionals, each responding from the perspective of their own subunit area of supply responsibility.

Findings - Both attentional disruption risk management perspectives are needed to achieve supply resilience, and neither is superior in terms of achieving supply resilience. Both the efficiency of the top down and exposure to the unexpected with the bottom up are needed - to a balanced degree - for improved supply resilience. Practical implications - The results encourage firms to purposefully develop their supply risk management practices, first, to include both perspectives and, second, to avoid biases in attentional selection for disruption detection. Ensuring a more balanced approach may allow firms to improve their supply resilience.
\end{abstract}

(C) Harri Lorentz, Sini Laari, Joanne Meehan, Michael Eßig and Michael Henke. Published by Emerald Publishing Limited. This article is published under the Creative Commons Attribution (CC BY 4.0) licence. Anyone may reproduce, distribute, translate and create derivative works of this article (for both commercial and non-commercial purposes), subject to full attribution to the original publication and authors. The full terms of this licence may be seen at $h$ ttp://creativecommons.org/licences/by/4.0/legalcode

The first two authors would like to thank the Finnish Foundation for Economic Education for financially supporting this research. 
Originality/value - The results contribute to the understanding of the microfoundations that underpin firms' operational capabilities for supply risk and disruption management and possible attentional biases.

Keywords Disruption, Risk management, Procurement, Supply, Attention-based view, COVID-19

Paper type Research paper

\section{Introduction}

Global supply disruption because of COVID-19 and its aftermath has been unprecedented in its scale and severity, and practitioners and scholars have been reminded of the criticality of supply risk management, which has led to renewed interest and appreciation in the subject (e.g. Butt, 2021; Chowdhury et al., 2021; Harland, 2021; Ivanov and Das, 2020; Sarkis, 2020). Anecdotal evidence suggest that effective responses to resilience during the pandemic have included, for example, listening to signals from suppliers, effective internal communication channels and risk management tools for visualising the multitier supply network and predicting specific nodes of vulnerability (Banker, 2020). The focus of the current study is on understanding the variety of approaches to supply disruption risk management for achieving effective responses to resilience, particularly in the COVID-19 context.

The concept of resilience, which here is defined as a firm's ability to recover quickly from supply chain disruptions (e.g. Blackhurst et al., 2011), is based on a rich body of knowledge in the supply chain field and a mature operationalisation (e.g. Wieland and Durach, 2021). For example, flexibility and redundancy as dimensions of supply chain resilience moderate the relationships between extended supply chains and disruption occurrence and between supply market risk and disruption occurrence, respectively (Zsidisin and Wagner, 2010). Research on resilience has also emphasised the need for firms to have an internal risk management infrastructure or the ability to reconfigure resources (Ambulkar et al., 2015). In the context of COVID-19, the recent discourse has emphasised the complexities at play at the micro, meso and macro levels in managing supply disruption risk (Azadegan and Dooley, 2021). In this vein and inspired by recent anecdotal accounts, the current study considers the antecedents of resilience under supply disruptions at the supply management subunit level (e.g. category of items as an area of supply management responsibility). The level of analysis reflects the contingent nature of supply management practices that depend on the nature of the synergy-generating groups or categories of items and the preferences and capacity of the manager. We suggest that a more nuanced understanding is needed regarding how managers approach the task of managing and mitigating supply disruption risk within their areas of supply responsibility for improved resilience.

For example, the debilitating effect of the COVID-19 pandemic on supply networks has led to calls for increased levels of supply network monitoring and mapping (Linton and Vakil, 2020; Choi et al., 2020). However, these resource-intensive practices do not appear to be part of the standard risk management processes of many managers or firms. The cost may prove to be a major inhibitor, even though novel digital applications from solution providers such as Resilinc ${ }^{\circledR}$ and riskmethods ${ }^{\circledR}$ may help remedy the problem (www.resilinc.com; www. riskmethods.net). In the context of low-probability and high-impact disruptions like a pandemic, Simchi-Levi et al. (2014) contrast the traditional risk management approaches that rely on paying attention to the probabilities and impacts of all potential disruption events with resource-intensive approaches involving supply network mapping and an analysis of the time to recovery of each node. They suggest that the focus on recoverability in the latter approach requires managers to pay attention to external and internal responses, making supply management independent of the triggering events and the need to pay attention to risk sources, as in the former approach. Leading firms, such as Ford Motor Company, have augmented their traditional risk analysis approach with such focus on network recoverability, with apparent success (Simchi-Levi et al., 2015).
Attention and supply disruption risk management 
IJOPM

41,13

A more nuanced understanding of the antecedents of resilience under supply disruption requires that managers' different - and potentially competing - attentional approaches to supply disruption risk management be uncovered (Craighead et al., 2007; Pettit et al., 2010). The capacity for managerial attention is, after all, limited, and difficult choices regarding attentional focus must be made. To contribute to the literature (e.g. Zsidisin and Wagner, 2010; Ambulkar et al., 2015) from this perspective, we adopt the attention-based view (ABV) of the firm (Ocasio, 1997) as a novel theoretical foundation for supply chain and procurement research (cf. Lorentz et al., 2019). Based on behavioural management theories (Simon, 1947; Cyert and March, 1963), the ABV concerns how decision makers selectively focus their attention on some aspects of situations and ignore others within their own domain or area of responsibility. How firms anticipate and react to disruption events emerges from what decision makers focus their attention on; simultaneously, the attention of a manager is situated in the resources, rules and structures of a firm (Ocasio, 1997). In line with methodological individualism that recognises the criticality of micro-level decisions (Hodgson, 2007), the ABV suggests that an individual's attentional processes collectively determine organisational action (Ocasio, 1997). Elaborating on the ABV in the supply disruption risk management context, the following research question guides our study:

How does the attention of procurement managers regarding supply disruption risk management contribute to supply resilience?

The present research assumes that attention determines the resource allocation, strategy and focus of supply disruption risk management; therefore, attention can be hypothesised as serving as an important antecedent of resilience under supply disruption. Our focus on attention contributes to the understanding of the microfoundations underpinning a firm's operational capability for supply risk and disruption management (Felin et al., 2012; Barney and Felin, 2013) within the context of the COVID-19 pandemic. The somewhat unique implications of COVID-19 may be expected because pandemics are not limited in terms of geographic regions or time periods (Ivanov and Das, 2020).

In the following sections, we conceptualise and define the constructs of the present study, paying particular attention to the attention-related antecedents of resilience and developing the hypotheses and research model. The methods of the multicountry survey and analysis procedures are described, and the results are reported. The conclusions drawn from a hierarchical regression analysis contribute to the knowledge base on supply disruption risk management and its capability microfoundations.

\section{Model development}

\subsection{Antecedent constructs}

We selectively draw on the key constructs of the ABV to conceptualise supply disruption risk management as an antecedent of resilience. The attentional perspectives of managers are the cognitive structures that define the resource allocation and strategies of firms as collectives (Ocasio, 2011) and organisational subunits, such as a category of products/services in procurement. Attentional perspectives as top-down-oriented goals, schemas or mental templates (Walsh, 1995; Ocasio, 2011) help managers achieve efficiency, predictability and reliability by directing attention only to those external issues expected to be important (Shepherd et al., 2017).

Attentional perspectives focus on preparation and proactive mitigation before disruption occurs (cf. Sheffi, 2005). From the literature, we can identify two distinctive constructs related to the use of top-down schemas and templates for supply disruption risk management. The first, a focus on supply risk sources, is defined as the use of schemas that direct managerial attention to specifying the possible risk sources and events (Zsidisin and Wagner, 2010), 
assessing the probability and impact and mitigating their potential effects (cf. Kleindorfer and Saad, 2005). Buyers' perceptions of supply risk, including the probability and magnitude of disruption, affect their decisions (Ellis et al., 2010).

The second, a focus on supply network recoverability, is the use of schemas that direct managerial attention to specifying and assessing recoverability through network mapping to increase resilience (Craighead et al., 2007; Simchi-Levi et al., 2014). In the wake of the COVID19 disruption, the virtues of supply chain mapping have been shown (Choi et al., 2020; Linton and Vakil, 2020). In a similar vein, the effects of supply network designs and complex structures on risk and recovery have received attention (Craighead et al., 2007; Kim et al., 2015; Bode and Wagner, 2015; Lorentz et al., 2016; Son et al., 2021). Some studies have also incorporated both perspectives in their research designs (Bode and Macdonald, 2016); however, in practice, the dividing lines between these perspectives are unclear (cf. Norrman and Jansson, 2004) because recoverability augments traditional risk analysis methods focused on sources (Simchi-Levi et al., 2015).

A second potential ABV-based high-level antecedent of resilience is attentional selection. Selectively attending to some stimuli and excluding others (Ocasio, 2011) can aid in the detection and recognition of risk events and disruptions (Craighead et al., 2007; Bode and Macdonald, 2016) to ensure a timely response (Bode and Macdonald, 2016). Here, the underlying attentional processes may be either top down or bottom up in nature. Top-down attentional processing draws on previously identified sources of risk or vulnerabilities, which serve as mental templates for purposefully monitoring, scanning and detecting disruption signals in the supply environment and network (Bode and Macdonald, 2016).

In contrast, bottom-up attentional processing is data or stimulus driven (Ocasio, 2011). Based on ad hoc, random, unpredictable and reciprocal interactions, bottom-up attentional processing captures attention on the aspects that are not actively sought for (Shepherd $e$ al., 2017). Bottom-up attentional processing for supply disruptions reacts to signals that may be unexpected or may occur at the outskirts of supply networks but that have the potential for cascading effects to create "supply chain tsunamis" (Akkermans and Wassenhove, 2018a). For example, the so-called grey swan events (already occurring but unlikely) may escape attention because the initial signals may be weak or require intelligent monitoring of "a few hundred variables outside the usual managerial radar screen" (Akkermans and Wassenhove, 2018b, p. 14).

In summary, top-down supply disruption detection approaches use top-down schemas for the focused scanning of predefined risk sources, and bottom-up supply disruption detection approaches deploy mechanisms for noticing and discovering unexpected signals regarding threats to supply disruptions. Because the literature confirms the heterogeneity in supply disruption risk management and performance outcomes (and even in the understanding of risk, Hekmann et al., 2015), we aim to provide a nuanced understanding of the antecedent capability of microfoundations to explain why different managers, acting within their area of supply responsibility, arrive at different supply disruption outcomes and resilience (cf. Felin et al., 2012). This goal is accomplished through an ABV lens, given that we suggest various disruption management outcomes "in part, because [managers] differ in how they [focus,] notice and interpret the stimuli around them" (Cho and Hambrick, 2006, p. 466).

\subsection{Hypotheses}

In the following section, testable hypotheses are developed linking ABV-based constructs with the dependent construct of supply resilience. Figure 1 depicts our research model.

True to our ABV-based definition, the two identified attentional perspectives on supply disruption risk management have different foci, yet their desired outcomes converge. In the absence of perspective-specific evidence, studies have identified the general positive effects of 
IJOPM

41,13

\section{6}

Figure 1.

Research model and hypotheses

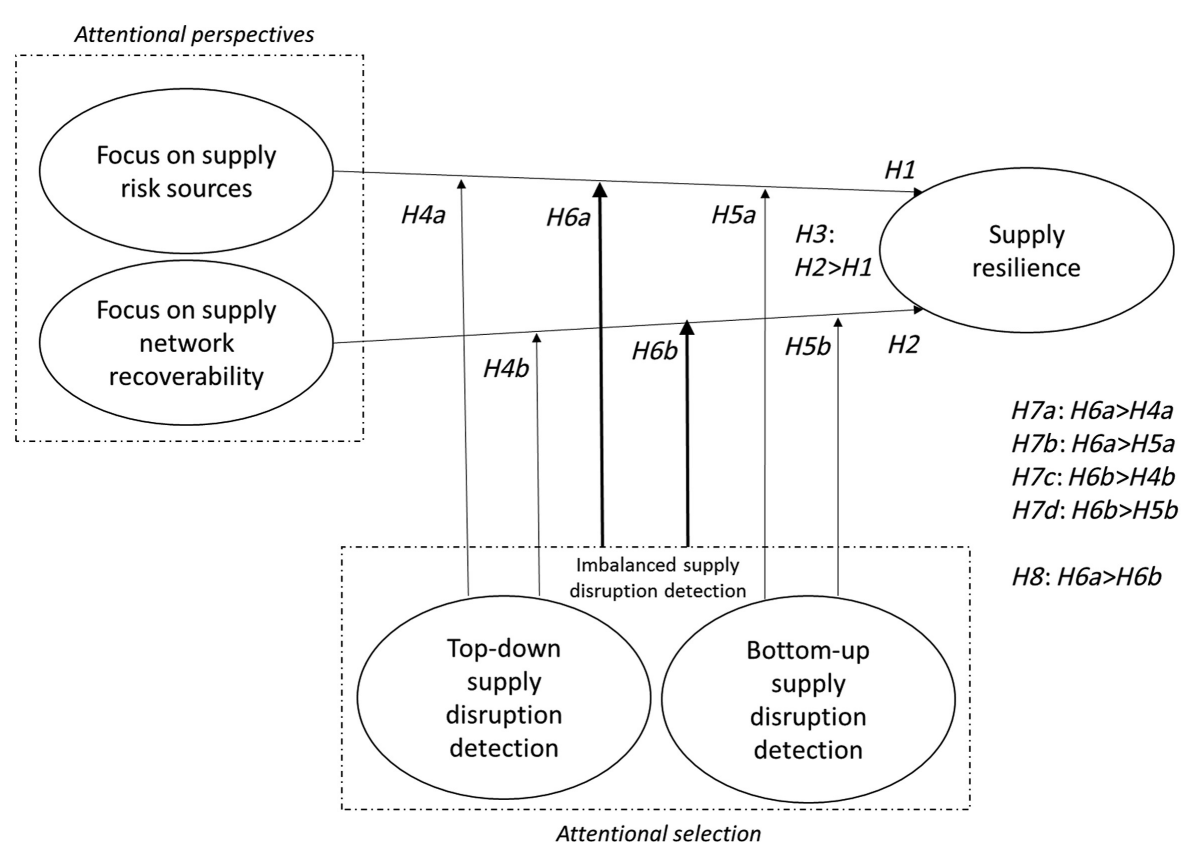

supply risk management. For example, holistic risk management practices along supply chains are positively related to operational performance (Kauppi et al., 2016), a generic risk management infrastructure plays an important role in resilience (Ambulkar et al., 2015), flexibility and redundancy practices moderate the effect of supply market risk on supply chain resilience (Zsidisin and Wagner, 2010), and disruption recovery capabilities may reduce the severity of supply disruptions (Craighead et al., 2007).

These conclusions suggest that many types of well-thought-out and maturely executed risk management practices improve resilience because according to the $\mathrm{ABV}$, they generate heightened awareness of the environment and are likely to lead to the allocation of resources so that the particular features may be addressed. Focus and awareness of risk sources, as an attentional perspective, directs adequately resourced managers to undertake the "Sam" tasks: the specifying, assessment and mitigation of sources of risks and vulnerabilities (Kleindorfer and Saad, 2005). With the assumed skilful execution of these tasks, beneficial resilience outcomes may be achieved (e.g. Ambulkar et al., 2015). Thus, we hypothesise the following:

H1. The focus on supply risk sources as an attentional perspective on supply disruption risk management is positively associated with supply resilience.

As another attentional perspective, a focus on supply network recoverability directs managers to map and assess network recoverability in terms of contingency plans and redundancy practices (Ivanov and Dolgui, 2019), for example, regarding inventory safety margins and alternative supply sources. Attention to recoverability with direct suppliers and across the supply network can lead to the standardisation of procedures, joint decisionmaking and collaborative performance systems, eventually leading to a higher level of resilience under supply disruptions (Friday et al., 2018). Thus, we state the following hypothesis: 
H2. The focus on supply network recoverability as an attentional perspective on supply disruption risk management is positively associated with supply resilience.

The key contribution of the current study is examining the variety of supply disruption risk management approaches to reveal the underlying theoretical nuances. With the ABV being used to provide the grounds for discriminating between the two attentional perspectives on supply disruption risk management, it is interesting to consider whether these perspectives differ in terms of the strength of their association with supply resilience.

Because supply network recoverability does not depend on identifying all possible risk sources (Simchi-Levi et al., 2014), it could be considered a more robust approach to resilience. Enabled by resource-intensive network mapping, this perspective is also more likely to involve collaborative practices towards suppliers, such as risk information sharing, risk and benefit sharing and process integration (Friday et al., 2018). Indeed, external integration or interorganisational orientation for supply risk management, here encompassing such collaborative practices, has been shown to result in higher operational performance (Kauppi et al., 2016) and lower levels of supply disruptions (Revilla and Saenz, 2017). A likely outcome of network mapping and analysis is a reduced dependency on the certainty of supply risk knowledge (Ivanov and Dolgui, 2019). The suggestion here is that the recoverability perspective may prove to be a more resilient approach to the focus on risk sources because the latter most likely fails to consider every possible contingency (Akkermans and Wassenhove, 2018b). Therefore, we state the following hypothesis:

H3. A focus on supply network recoverability has a stronger association with supply resilience compared with the association of focus on supply risk sources with supply resilience.

Attentional selection is the capacity to detect and recognise emergent risk events and disruptions (Craighead et al., 2007; Bode and Macdonald, 2016) - even environmental research shows evidence of making use of detection systems for low-frequency, high-impact events (Abadie et al., 2017). A strong warning capability can reduce the severity of supply chain disruptions (Craighead et al., 2007) and improve a firm's recovery capability (Shao, 2013). Partial support has been found for the direct effect of warning capability on operational performance and full support for the mediated effect via recovery capability (Riley et al., 2016). Furthermore, related to early warning systems and active environmental scanning, market orientation may play a role in risk mitigation and response through supply chain agility (Braunscheidel and Suresh, 2009). Fast disruption detection appears to be beneficial in general (cf. Sheffi, 2005), suggesting the importance of both top-down and bottom-up attentional processing. Drawing on the evidence of the moderating benefits of warning capability on supply resilience (Craighead et al., 2007), we can hypothesise a moderating role, essentially suggesting that detection practices of any kind enhance supply risk management efforts.

More specifically, top-down attentional processing draws on the identified sources of risk and vulnerabilities or the known nexus suppliers in the network (Yan et al., 2015). Therefore, the routines related to top-down supply disruption detection seem to be a natural match for the focus on supply risk sources. In practice, once the risk sources have been identified, assessed and mitigated, they can be monitored for disruption signals, leading to resilience as an outcome. Similarly, top-down supply disruption detection routines may also enhance the focus on supply network recoverability because the identification and monitoring of vulnerable nexus suppliers may result in a more timely and effective response, for example, in terms of orders and production quantities in the network (Simchi-Levi et al., 2018). Thus, we state the following hypotheses:
Attention and supply disruption risk management 
IJOPM

41,13

H4a. Top-down supply disruption detection enhances the positive association between the focus on supply risk sources and supply resilience.

H4b. Top-down supply disruption detection enhances the positive association between the focus on supply network recoverability and supply resilience.

For bottom-up attentional processing, the mechanisms for improved resilience are different. The purpose of bottom-up attentional processing is to notice those aspects in the environment for which there are no attention-directing guidance and that are not actively sought for (Shepherd et al., 2017). The bottom-up attentional processing for supply disruption detection complements the attentional perspective with a focus on supply risk sources, here with the additional exposure to the unexpected sources and signals for disruptions. In terms of enhancing the attentional perspective of focus on supply network recoverability, bottom-up supply disruption detection is likely to result in a more timely and effective response to unexpected disruption signals, for example, in terms of adjustments to production capacity allocation (Simchi-Levi et al., 2018). Hence, we state the following hypotheses:

H5a. Bottom-up supply disruption detection enhances the positive association between focus on supply risk sources and supply resilience.

H5b. Bottom-up supply disruption detection enhances the positive association between focus on supply network recoverability and supply resilience.

To elaborate on the supply disruption risk management approaches from the perspective of the $\mathrm{ABV}$, the possible preference of one type of attentional selection over the other must be considered. Top-down detection is primarily based on existing frameworks and tools and, by its very definition, provides a limited scope for environmental scanning. Furthermore, topdown attentional selection, which is based on prior experience, implies potential risks of bias (Schultz-Hardt et al., 2000) and can be limited to incremental changes in trajectories that neglect phenomena outside the manager's peripheral vision (Shepherd et al., 2017; cf. Day and Schoemaker, 2004). Therefore, top-down detection is ill-suited for detecting so-called grey swans "in the outskirts of the extended supply chains of an organisation" (Akkermans and Van Wassenhove, 2018a, p. 71). However, despite these shortcomings, top-down selection is superior in terms of its efficiency and reliability in detecting disruption signals in known and prioritised areas (Shepherd et al., 2017).

By contrast, bottom-up attentional selection has greater potential to identify discontinuous changes and disruptions (Shepherd et al., 2017; cf. Day and Schoemaker, 2004), including grey swans (Akkermans and Van Wassenhove, 2018a). The early detection of unanticipated and developing disruptions is of crucial importance, but here, there is tension because bottom-up attentional selection lacks efficiency and reliability in detecting potentially crucial signals in already recognised risk areas compared with top-down approaches. Therefore, managers must balance their attentional selection, similar to what has been theorised in the context of organisational-level ambidexterity (Birkinshaw and Gupta, 2013). Instead of balanced proficiency for exploitation and exploration, figuratively speaking, the hands of the organisation - the managers in this case - and the firms as collectives metaphorically must keep both eyes open for monitoring the known and detecting the unexpected (Lorentz et al., 2019). Nevertheless, because companies typically prefer efficiency in the absence of slack resources (Lavie et al., 2010), managers may emphasise top-down attentional selection over bottom-up attentional selection, creating an imbalance.

We develop the construct imbalanced supply disruption detection by calculating the absolute difference of the attentional selection types, that is, $|A-B|$, which suggests that the higher the absolute difference, the more imbalanced the attentional selection will be (cf. Birkinshaw and Gupta, 2013). Therefore, the key to the beneficial effect is allocating the 
available scarce resources in equal measure to both selection types to avoid bias, or imbalance. Imbalance in detection routines is hypothesised to diminish the beneficial effect of both types of attentional perspectives. However, we must assume that those cases in which an approximate balance is achieved are predominantly of the type in which both top down and bottom up are at a relatively high level (Assumption 1), creating an important boundary condition for generalisation on the superiority of balanced attentional selection (cf. Busse et al., 2017). This is because doing nothing in both dimensions, that is, in a balanced way, will barely result in better performance compared with a case that demonstrates heavy imbalance towards, for example, the top down (Junni et al., 2013). The following hypotheses are stated:

Attention and supply disruption risk management

H6a. Imbalanced supply disruption detection diminishes the positive association between the focus on supply network risk sources and supply resilience.

H6b. Imbalanced supply disruption detection diminishes the positive association between the focus on supply network recoverability and supply resilience.

We consider whether the moderating effect of the imbalance construct is more significant compared with the effects of the separate attentional selection constructs, given that bias towards one type of attentional selection may be avoided with balancing. Supply resilience is weaker when the benefits of the exposure to the unexpected or efficiency of focused monitoring are missing entirely or are significantly lacking with inadequate resourcing. The following set of four hypotheses will guide us in testing the comparative significance of the imbalanced construct's effect compared with the separate top-down and bottom-up detection constructs. First, the moderating effects on the focus on the supply risk sources perspective are compared:

$H 7 a$. The effect of imbalanced supply disruption detection on the association between the focus on supply risk sources and supply resilience is greater compared with the enhancing effect of top-down supply disruption detection.

$H 7 b$. The effect of imbalanced supply disruption detection on the association between the focus on supply risk sources and supply resilience is greater compared with the enhancing effect of bottom-up supply disruption detection.

Second, the enhancing moderating effects on the focus on supply network recoverability perspective are compared:

$H 7 c$. The effect of imbalanced supply disruption detection on the association between the focus on supply network recoverability and supply resilience is greater compared with the enhancing effect of top-down supply disruption detection.

$H 7 d$. The effect of imbalanced supply disruption detection on the association between the focus on supply network recoverability and supply resilience is greater compared with the enhancing effect of bottom-up supply disruption detection.

Finally, the next logical step is to consider whether imbalance affects - to a greater degree one or the other of the attentional perspectives on supply risk management. In developing the hypothesis for understanding such construct interactions, we can assume that imbalance in attentional selection, if any, is typically tilted towards the top down (Assumption 2). This type is more efficient (Shepherd et al., 2017), and its limited scope is preferred by resourceconstrained managers. Thus, the balancing effort of bottom-up attentional selection fills possible gaps in defences. A focus on recoverability stands to gain relatively less, as the supply network should be able to survive unexpected events, assuming properly executed predisruption analyses and consequent redundancy building efforts. We state the following hypothesis: 
IJOPM

41,13
H8. Imbalance in supply disruption detection diminishes the positive association of the focus on supply risk sources with supply resilience to a greater degree compared with its diminishing effect on the association between the focus on supply network recoverability and supply resilience.

\section{Methods}

\subsection{Measurement}

Drawing from the conceptual foundations of the two dimensions of attentional perspectives and two dimensions of attentional selection, we have developed novel procurement-specific questionnaire items because there were no existing operationalisations. In the present study, attentional perspectives describe the cognitive structures that define the focus of supply risk management in the area of supply management responsibility. The focus on supply risk sources captures the use of schemas and templates that direct managerial attention to specifying, assessing and mitigating the potential effects of risk sources (Kleindorfer and Saad, 2005; Fan et al., 2016). The focus on supply network recoverability captures how managerial attention is allocated to specify and evaluate recoverability and proactively mitigate the effects of network vulnerabilities (e.g. Simchi-Levi et al., 2014). The items and descriptive statistics are shown in Appendix. For the top-down and bottom-up supply disruption detection items, we drew on the works of Shepherd et al. (2017) and Lorentz et al. (2019), with the latter being in alignment in terms of the collaboration dimension with both Chaudhuri et al. (2020) and Friday et al. (2018). For the outcome side of the supply resilience construct, the firm resilience measurement scale from Ambulkar et al. (2015) was adopted, with modifications to fit the procurement context, specifically in the areas of supply management responsibility (categories of items), as the unit of analysis.

The survey questions considered the current states and practices during the COVID-19 pandemic (supply resilience) or during the past year (other constructs) in the respondent's area of supply management responsibility (e.g. a category of items). The measures used a seven-point Likert scale, as follows: (1) completely disagree, (2) mostly disagree, (3) somewhat disagree, (4) neither agree nor disagree, (5) somewhat agree, (6) mostly agree and (7) completely agree. Two control variables - turnover and COVID-19 impact - were measured as categorical single items. Turnover was measured with a four-category variable: (1) $0-2$ million EUR, (2) 2.1-10 million EUR, (3) 10.1-50 million EUR and (4) over 50 million EUR. For the negative COVID-19 impact, the respondents evaluated the impact of the COVID-19 pandemic on the supply chain/supplier network of their category or item on a seven-point scale: (1) no impact, (2) negligible impact, (3) minor impact, (4) moderate impact, (5) major impact, (6) severe impact and (7) catastrophic impact.

\subsection{Pretest procedure for attentional perspective and attentional selection scales}

The initial versions of the survey items and constructs were presented to industry experts to ensure their content validity, and the wording was refined based on their feedback. In May 2020, an invitation to participate in a pilot survey was sent to a convenience sample of 34 procurement professionals in the authors' professional networks. In total, 21 useable responses were collected. The participants were asked to complete the questionnaire and provide feedback on the items and survey layout. In an exploratory factor analysis, five factors were extracted as expected. Based on the factor loadings and comments of the participants, minor adjustments were made prior to the full launch of the survey. 


\subsection{Data collection}

Data were collected in Finland, the UK, and Germany. In Finland, the online questionnaire was launched in May 2020, and in the UK and Germany, this was carried out in June 2020. The respondents were expected to have a broad range of knowledge and pragmatic, experiencebased insights into the topic within their domain of responsibility (Montabon et al., 2018). In Finland and the UK, invitations to participate were sent to experienced procurement professionals in the authors' networks. In Germany, the invitation was sent as part of a BME newsletter (the Association of Supply Chain Management, Procurement and Logistics). The use of single respondents was justified because the unit of analysis was each informant's area of supply management responsibility, such as the category of spend (Krause et al., 2018). Indeed, the informants were procurement professionals who were knowledgeable about their own micro-level procurement decisions that affect supply resilience (Montabon et al., 2018); hence, they can be described as "purchasing decision-makers" (Wouters et al., 2005, p. 177). Furthermore, our research question focused on subunit-level approaches limited to the respondents' own domain of management in one functional area of a firm, and we employed monadic constructs; therefore, a single-source research design would be less likely to suffer from respondent bias (Flynn et al., 2018).

The final number of responses was 190. The sample covered a wide variety of industries, with the majority operating in manufacturing. The respondent profiles are depicted in Table 1 and are deemed representative with sufficiently high levels of the respondents' experience.

The respondents were assured of their confidentiality and anonymity. After completing the survey, the respondents could choose to receive an invitation to a webinar; however, their email addresses and survey responses could not be matched. Early and late respondents were compared across theoretical constructs and demographic variables with an independent samples $t$-test (Armstrong and Overton, 1977). The $t$-test showed no significant differences between the early and late respondents ( $p$-values between 0.232 and 0.546 ), indicating that significant nonresponse bias did not influence the results (Anderson and Gerbing, 1988).

Turnover

0-2 million EUR

2.1-10 million EUR

10.1-50 million EUR

Over 50 million EUR

Country

Finland

Germany

UK

Other

Respondent's position

Top management

Head of function

Manager

Specialist

Assistant

Work experience at the current employer

Mean

8
44
81
57

135
13
32
10

135

13

10

29

51

68

40

1

$9.47[0 ; 40]$

\author{
Industry
}

Food, beverages, and Tobacco 16

Textiles and apparel 3

Wood 3

Paper 4

Printing 1

Chemicals and petrochemicals $\quad 7$

Pharmaceuticals 9

Rubber and plastic 3

Non-metallic mineral products 3

Basic metals $\quad 22$

Electronics $\quad 19$

Machinery and equipment $\quad 25$

Transport equipment 8

Furniture and other manufacturing $\quad 5$

Repair and installation $\quad 1$

Construction 13

Wholesale $\quad 6$

Retail 3

Services $\quad 14$

Public sector $\quad 17$

Other 8

\section{Attention and supply disruption risk management}

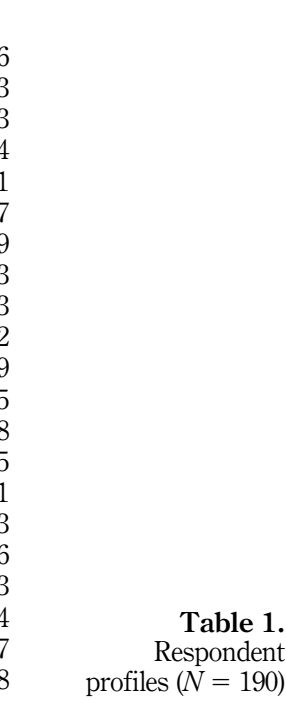


IJOPM

41,13

162

\subsection{Common method variance}

Common method variance (CMV) can exist at relatively high levels $(70 \%$ or more) before it induces significant biases (Fuller et al., 2016). Nevertheless, several procedural and methodological remedies have been taken to avoid CMV. As suggested by Podsakoff et al. (2003), the independent and dependent variables were placed in different sections of the questionnaire. The percentage of supply originating from the European Union was used as a theoretically unrelated marker variable to estimate method bias (Lindell and Whitney, 2001; Williams et al., 2010). We performed a modified Lindell and Whitney test where the mean correlation between the marker variable and other variables (0.041) was used to adjust the correlation coefficients and test their significance (Lindell and Whitney, 2001). The modified approach decreased the risk that the smallest correlation between the marker variable and other variables would have occurred by chance. All significant values remained significant after the partial correlation adjustment, suggesting that CMV was not a serious issue in the study (see Table 2).

To address potential endogeneity of the exogenous variables in our model, we performed a Durbin-Wu-Hausman test (see Lu et al., 2018) with the work experience of the respondent as an instrumental variable. The parameter estimates for the residuals were nonsignificant, supporting the assumption of exogeneity. Finally, we conducted Little's MCAR test. Based on the results, the missing values in the data were missing completely at random $\chi^{2}=248.844$, $\mathrm{df}=224, p=0.122)$.

\section{Analysis and results}

\subsection{Descriptive results for evaluating the underlying assumptions}

To characterise the sample in terms of balancing the attentional selection constructs among the respondents - thus addressing Assumptions 1 and 2 - we divided the IMBALANCE variable into three categories: Top-down dominant (i.e. TOP DOWN > BOTTOM UP), Bottom-up dominant (i.e. BOTTOM UP $>$ TOP DOWN) and Balanced (i.e. $-0.25 \leq$ [TOP DOWN - BOTTOMUP] $\leq 0.25$ ). Here, $42 \%$ of the respondents were top-down dominant, $30 \%$ were bottom-up dominant, and $28 \%$ were balanced (Table 3 ).

Within the balanced group, the mean values of TOP DOWN and BOTTOM UP were rather high. Upon closer inspection of this group, we can conclude that our sample did not include cases where both TOP DOWN and BOTTOM UP were at a low level, a situation that could affect the results (Junni et al., 2013). This suggests the applicability of our hypotheses regarding the imbalance construct because we have stayed well within the boundary condition (Assumption 1 supported). The results also imply that most of our sample did not demonstrate balanced supply disruption detection and that there was, contrary to Assumption 2, a sizeable group of respondents in which the imbalance was tilted towards the bottom up. We note that this may have an impact on the results regarding H8.

Table 2.

Zero-order correlations and adjusted correlations of the major variables

\begin{tabular}{llcccc}
\hline & Source & Recoverability & Top-down & Bottom-up & Resilience \\
\hline Source & 1 & $0.491^{* *}$ & $0.502^{* *}$ & $0.473^{* *}$ & $0.170^{* *}$ \\
Recoverability & $0.512^{* *}$ & 1 & $0.579^{* *}$ & $0.528^{* * *}$ & $0.201^{* *}$ \\
Top-down & $0.523^{* *}$ & $0.596^{* *}$ & 1 & $0.584^{* *}$ & 0.088 \\
Bottom-up & $0.495^{* *}$ & $0.547^{* *}$ & $0.601^{* *}$ & 1 & $0.303^{* *}$ \\
Resilience & $0.204^{* *}$ & $0.234^{* *}$ & 0.126 & $0.332^{* *}$ & 1 \\
Marker variable & 0.017 & 0.047 & 0.022 & 0.079 & -0.073 \\
Note(s): Zero-order correlations are below the diagonal; adjusted correlations are above the diagonal \\
$* * p<0.01$
\end{tabular}




\subsection{Measurement model}

First, we conducted an exploratory factor analysis using a principal components analysis with a Varimax rotation. The results are shown in Table 4. The Kaiser-Meyer-Olkin (KMO) test (0.901) and Bartlett's test of sphericity (2735.386, $\mathrm{df}=210, p<0.001)$ suggested sampling adequacy and validity of the measurement scale. As expected, five factors with eigenvalues of more than 1 were extracted. The five factors explained a cumulative variance of 76.216 .

A confirmatory factor analysis was performed to assess the psychometric properties of the measurement scales. The goodness-of-fit indices (Table 5) suggested that the measurement model fits the data appropriately $\left(X^{2} / \mathrm{df}=1.768, \mathrm{CFI}=0.950\right.$, TLI $=0.935$, RMSEA $=0.064, p$-value $=0.027$ ) (Hu and Bentler, 1999). All items loaded on the respective constructs. The standardised factor loadings were significant and ranged from 0.679 to 0.924 , mostly exceeding the recommended threshold of 0.7 (Hair et al., 2010). Item TOP4 was just below 0.7 and hence retained. All the constructs demonstrated convergent validity and acceptable reliability and internal consistency (average variance extracted $>0.50$; composite reliability >0.70) (Fornell and Larcker, 1981; Garver and Mentzer, 1999).

Discriminant validity was evaluated following the guidelines of Voorhees et al. (2016). The square root of AVE (displayed on the diagonal of Table 6) was compared with the correlations between each construct (Fornell and Larcker, 1981) and found to be greater than the zeroorder correlations with other latent constructs, thereby confirming discriminant validity.

In addition, we used the heterotrait-monotrait test (HTMT), which is a superior method for assessing discriminant validity compared with the conventional constrained Phi approach (Henseler et al., 2015; Voorhees et al., 2016). All HTMT ratios were found to be below 0.85 (Table 7), providing evidence of discriminant validity (Henseler et al., 2015; Voorhees et al., 2016).

Because the data were collected from three countries, measurement equivalence was ensured by following the steps outlined by Wiengarten et al. (2012): calibration, translation and metric equivalence. The measurement units on the seven-point Likert scales did not require calibration across countries, and their associated explanations (completely disagree to completely agree) could be universally understood. Regarding translation equivalence, the questionnaire was designed simultaneously in English and Finnish and later translated into German by two native speakers. Versions were compared and refined when necessary. To assess the metric equivalence, Cronbach's alphas were calculated separately for each measurement scale by country. The variance of alpha values was below the threshold of 0.10 , indicating consistent scoring across countries (Rungtusanatham et al., 2005; Wiengarten and Pagell, 2012).

\begin{tabular}{llccc}
\hline & & Top-down dominant (42\%) & Bottom-up dominant (30\%) & Balanced (28\%) \\
\hline SOURCES & Mean & 4.803 & 4.775 & 5.113 \\
& SD & 1.370 & 1.102 & 1.567 \\
RECOVERABILITY & Mean & 3.488 & 3.368 & 4.215 \\
TOP-DOWN & SD & 1.422 & 1.217 & 1.574 \\
& Mean & 4.901 & 3.865 & 4.696 \\
BOTTOM-UP & SD & 1.075 & 1.306 & 1.376 \\
RESILIENCE & Mean & 3.640 & 4.930 & 4.701 \\
& SD & 1.307 & 1.222 & 1.344 \\
& Mean & 5.326 & 5.755 & 5.740 \\
& SD & 1.221 & 0.868 & 1.121
\end{tabular}

Attention and supply disruption risk management 


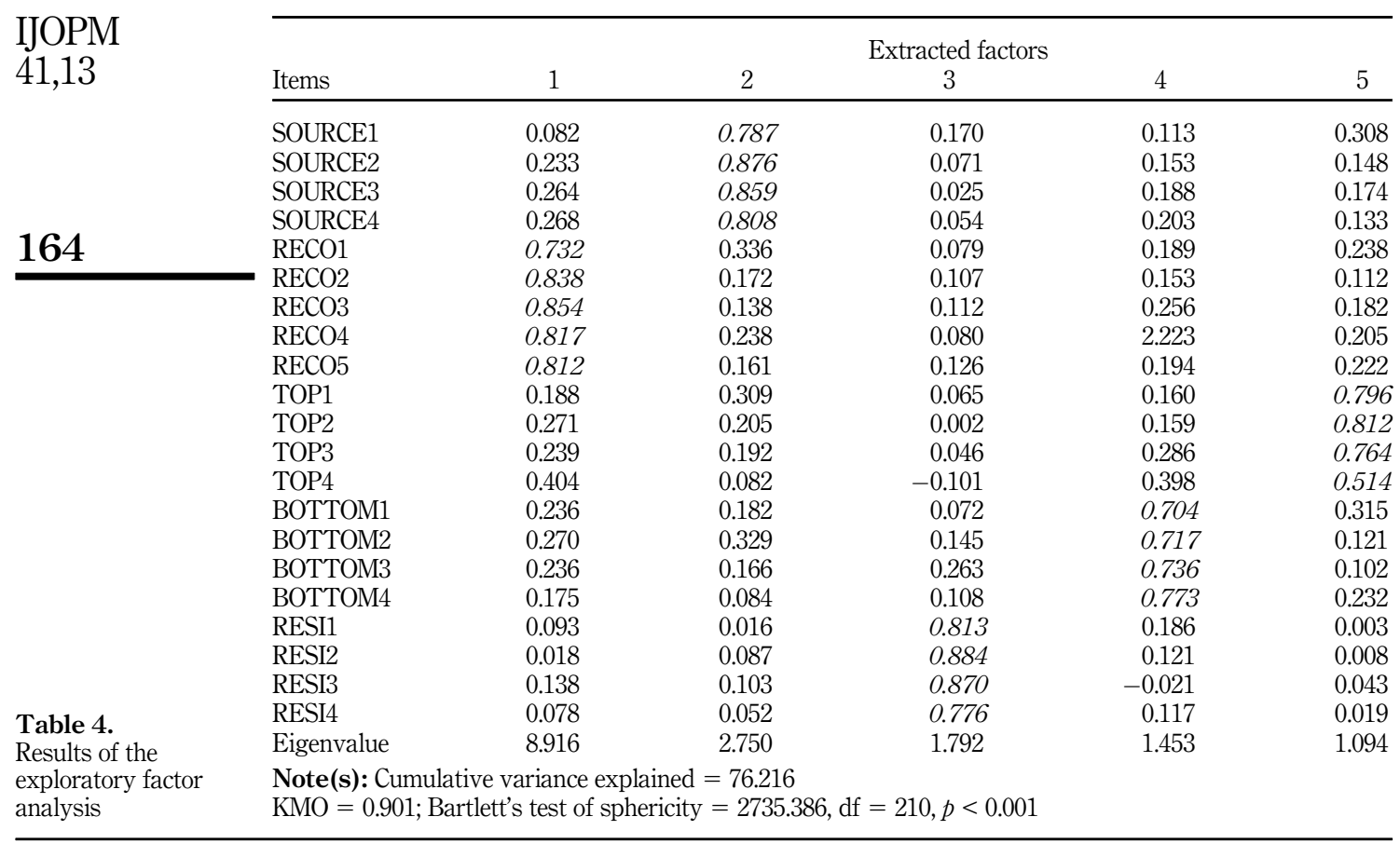

\subsection{Regression results}

Table 8 outlines the results of several hierarchical regression models. The assumptions of linear regression were first tested. The absolute values for univariate skewness and kurtosis were below the recommended thresholds of 2 and 7, respectively (Curran et al., 1996). Standardised residuals were plotted against the standardised predicted values, which supported linearity and equality of variances (Hair et al., 2010). To avoid multicollinearity issues, the independent and dependent variables were standardised before being entered into the regression model. The variance inflation factors (VIF) are presented in Table 5, and apart from one item (RECO3), they are below the commonly accepted threshold value of 5 . Because we detected the existence of heteroscedasticity through the Breusch-Pagan test $(p<0.01)$ we used robust standard error terms.

In addition to the base model (only control variables), there are five models: Model 1 includes the main effects, Model 2 adds TOP DOWN and BOTTOM UP as moderators, Model 3 adds the interaction terms, Model 4 adds IMBALANCE as the moderator, and Model 5 adds the interaction term of IMBALANCE. All models exceeded the threshold of 0.80 for statistical power, implying that the sample size is adequate to support hypothesis testing (MacCallum et al., 1996).

Regarding the control variables, firm size in terms of TURNOVER plays a role in only some of the alternative models, with $p<0.10$. Thus, the relatively weak associations of TURNOVER with SUPPLY RESILIENCE are not discussed further. By contrast, the data suggest that COVID-19 IMPACT has had a negative effect on SUPPLY RESILIENCE across the observed alternative models, predominantly at the $p<0.01$ level, indicating the salient association of these variables. 


\begin{tabular}{|c|c|c|c|c|c|}
\hline Latent variables & $\mathrm{VIF}$ & $\begin{array}{l}\text { Unstandardised factor } \\
\text { loading }\end{array}$ & $\begin{array}{l}\text { Completely standardised factor } \\
\text { loading }\end{array}$ & $t$-value & $\begin{array}{l}\text { Attention and } \\
\text { supply }\end{array}$ \\
\hline \multicolumn{5}{|c|}{ Focus on supply risk sources $(\alpha=0.913, C R=0.911, A V E=0.721)$} & tion risk \\
\hline SOURCE1 & 2.600 & 1.000 & 0.759 & $-^{\mathrm{a}}$ & management \\
\hline SOURCE2 & 4.261 & 1.273 & 0.893 & 13.106 & \\
\hline SOURCE3 & 4.908 & 1.260 & 0.924 & 13.546 & \\
\hline SOURCE4 & 3.291 & 1.068 & 0.810 & 11.662 & 165 \\
\hline \multicolumn{5}{|c|}{ Focus on supply network recoverability $(\alpha=0.934, C R=0.935, A V E=0.744)$} & \\
\hline RECO1 & 3.301 & 1.000 & 0.827 & $-^{\mathrm{a}}$ & \\
\hline $\mathrm{RECO} 2$ & 3.535 & 0.954 & 0.843 & 14.082 & \\
\hline RECO3 & 5.227 & 1.049 & 0.910 & 15.935 & \\
\hline RECO4 & 4.335 & 0.988 & 0.891 & 15.380 & \\
\hline RECO5 & 3.478 & 0.924 & 0.838 & 13.975 & \\
\hline \multicolumn{6}{|c|}{ Top-down supply disruption detection $(\alpha=0.860, C R=0.884, A V E=0.658)$} \\
\hline TOP1 & 3.023 & 1.000 & 0.891 & $\mathrm{-a}^{\mathrm{a}}$ & \\
\hline TOP2 & 2.711 & 1.041 & 0.830 & 12.919 & \\
\hline TOP3 & 2.932 & 0.971 & 0.829 & 12.893 & \\
\hline TOP4 & 2.182 & 0.888 & 0.679 & 9.921 & \\
\hline \multicolumn{6}{|c|}{ Bottom-up supply disruption detection $(\alpha=0.853, C R=0.860, A V E=0.605)$} \\
\hline BOTTOM1 & 2.482 & 1.000 & 0.797 & $-^{\mathrm{a}}$ & \\
\hline BOTTOM2 & 2.606 & 1.092 & 0.812 & 11.632 & \\
\hline BOTTOM3 & 2.306 & 1.015 & 0.764 & 10.860 & \\
\hline BOTTOM4 & 2.122 & 1.064 & 0.736 & 10.403 & \\
\hline \multicolumn{6}{|c|}{ Supply resilience $(\alpha=0.876, C R=0.879, A V E=0.647)$} \\
\hline RESI1 & 2.339 & 1.000 & 0.796 & $-^{\mathrm{a}}$ & \\
\hline RESI2 & 3.054 & 1.251 & 0.871 & 12.745 & \\
\hline RESI3 & 2.854 & 1.149 & 0.823 & 12.047 & \\
\hline RESI4 & 1.985 & 1.059 & 0.720 & 10.258 & $\begin{array}{l}\text { lable } 5 \text {. } \\
\text { Results of the }\end{array}$ \\
\hline \multicolumn{5}{|c|}{$\begin{array}{l}\text { Note(s): }{ }^{\text {a Fixed for scaling }} \\
\chi^{2} / \mathrm{df}=1.768, \mathrm{CFI}=0.950, \mathrm{TLI}=0.935, \mathrm{RMSEA}=0.064 ; p \text {-value }=0.027\end{array}$} & $\begin{array}{r}\text { confirmatory factor } \\
\text { analysis }\end{array}$ \\
\hline
\end{tabular}

\begin{tabular}{|c|c|c|c|c|c|c|}
\hline & Source & Recoverability & Top-down & Bottom-up & Resilience & \\
\hline Source & 0.849 & & & & & \\
\hline Recoverability & $0.512 * *$ & 0.863 & & & & \\
\hline Top-down & $0.523^{* * *}$ & $0.596^{* *}$ & 0.811 & & & \\
\hline Bottom-up & $0.495 * *$ & $0.547 * *$ & $0.601 * *$ & 0.778 & & Discriminant validity \\
\hline Resilience & $0.204^{* *}$ & $0.234 * *$ & 0.126 & $0.332 * *$ & 0.804 & test with the Fornell \\
\hline \multicolumn{6}{|c|}{ Note(s): $* * p<0.01$, the square root of AVE appears on the diagonal in italic } & Larcker criterion \\
\hline
\end{tabular}

\begin{tabular}{lccccr}
\hline & Source & Recoverability & Top-down & Bottom-up & Resilience \\
\cline { 1 - 2 } $\begin{array}{lcccc}\text { Source } \\
\text { Recoverability }\end{array}$ & 0.547 & & & & \\
Top-down & 0.569 & 0.687 & & & Table 7. \\
Bottom-up & 0.533 & 0.622 & 0.707 & & Discriminant validity \\
Resilience & 0.233 & 0.269 & 0.165 & 0.396 & test with HTMT ratios \\
\hline
\end{tabular}




\section{IJOPM \\ 41,13}

166

Table 8.

Regression models for hypothesis testing

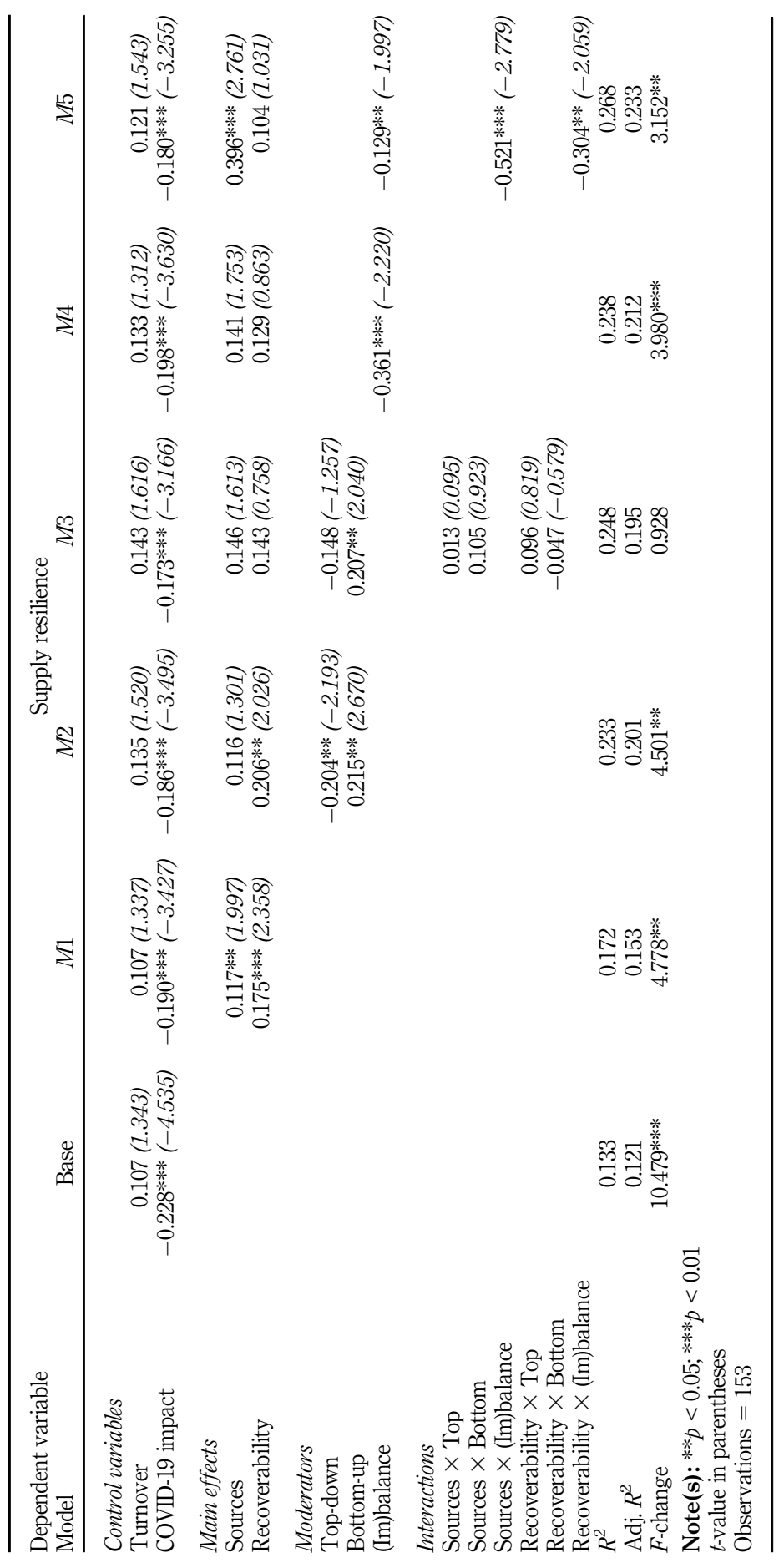


SOURCES and RECOVERABILITY both have a significant positive association with SUPPLY RESILIENCE; thus, both $\mathrm{H} 1$ and $\mathrm{H} 2$ are confirmed (see $M 1$ ). Interestingly, if SOURCES and RECOVERABILITY exist without TOP DOWN and BOTTOM UP (M1), the attentional perspective on network recoverability demonstrates a higher coefficient. When disruption detection constructs are added, SOURCES becomes more important than RECOVERABILITY.

A Wald test was used to evaluate H3. However, there was no statistically significant difference between the coefficients of these independents $(W=0.407, p=0.342)$, so H3 can be refuted. Essentially, both attentional perspectives on supply disruption risk management contribute to increased supply resilience, yet the data do not suggest the superiority of either attentional perspective in terms of its beneficial impact.

We considered the two attentional selection constructs separately (TOP DOWN, BOTTOM UP), as well as their role as moderators in the association between the independent variables and the SUPPLY RESILIENCE variable. Contrary to H4a and H4b, the data do not support the hypothesised role of TOP DOWN as a moderator ( $M 3)$, and similar conclusions must be drawn regarding H5a and H5b. Therefore, neither attentional selection type regarding disruption detection enhances the beneficial impacts of the supply risk management perspectives on supply resilience. In other words, with separate attentional selection constructs, the moderating role of disruption detection cannot be confirmed.

The hypotheses relating to the attentional selection construct of IMBALANCE, in which TOP DOWN and BOTTOM UP are combined, was tested by calculating the absolute difference of the component constructs. It was hypothesised that imbalance in the levels of the two types of attentional selection for supply disruption detection would be detrimental and that it would diminish the effects of SOURCES and RECOVERABILITY on SUPPLY RESILIENCE. Thus, in terms of the values of IMBALANCE, the lower the value, the better. A look at M5 indicates that both H6a and H6b can be supported by our data. This outcome suggests that IMBALANCE serves as a negative moderator for both attentional perspectives regarding supply risk management. In particular, the higher the difference is between the underlying components of IMBALANCE, the lower the SUPPLY RESILIENCE will be. These key results are statistically significant at the minimum level of $p<0.05$. The results suggest the importance and synergistic impact of the combined top-down and bottom-up attentional selection types on supply disruption detection.

To test H7a-d, a seemingly unrelated regression (SUR) analysis was simultaneously performed on $M 3$ and $M 5$. SUR is best used when (1) some coefficients are the same or zero, (2) the disturbance terms are correlated, or (3) a set of the same independent variables are used across models (Zellner, 1962; Habermann et al., 2015). The regression coefficients were then tested with $\mathrm{a} z$ test. The test statistics for $\mathrm{H7a}(z=0.526, p=0.599), \mathrm{H} 7 \mathrm{~b}(z=0.584, p=0.559)$, H7c $(z=0.169, p=0.866)$ and H7d $(z=0.434, p=0.665)$ were not significant; hence, H7a-d can be refuted.

The model with BALANCE as a moderator (M5) also has better $R$-square value and a significant $F$-change value compared with the base model, including only the control variable COVID-19 IMPACT and the main effects model (M1). Adding balanced attentional selection to the model, here reflecting disruption detection and warning capability, thus adds value in terms of supply resilience. To further assess the importance of achieving balance, we created a cumulative sum of TOP DOWN and BOTTOM UP and a product of TOP DOWN $\times$ BOTTOM UP while replacing IMBALANCE with these new constructs in the regression analyses. The coefficients of either the sum or the product construct in $M 4-M 5$ are not statistically significant, further underscoring the importance of balancing the two attentional selection types within the earlier specified boundary conditions (assumption 1). In conclusion, balanced attentional selection seems superior when used together with either of the two
Attention and supply disruption risk management 
IJOPM

41,13

\section{8}

attentional perspectives on supply risk management: the focus on risk sources or on network recoverability.

Finally, regarding H8, the coefficient for SOURCE $\times$ IMBALANCE interaction $(-0.521$, significant at $p<0.05$ level; M5) appears stronger compared with the coefficient for RECOVERABILITY $\times$ BALANCE interaction $(-0.129$ significant at $p<0.05$ level; $M 5)$, suggesting that balanced disruption detection plays a more salient role when there is a focus on supply risk sources. However, the difference is not statistically significant in a Wald test $(W=0.602, p=0.274)$. Therefore, our data do not conclusively support the hypothesis regarding the superior fit of BALANCE with one or the other of the independents; thus, H8 can be refuted (see Figure 2).

\section{Discussion and conclusions}

\subsection{Theoretical implications}

The results of the current research have several interesting theoretical implications regarding the attentional antecedents and enablers of supply resilience. First, our data do not reveal the superiority of either attentional perspective to supply disruption risk management in terms of achieving supply resilience. Having a focus on supply risk sources represents the "traditional methods for managing supply risk" that rely on identifying and understanding the probabilities of occurrence and severity of impact "for every potential event", whereas the focus on recoverability is about supply network mapping and an analysis of the time to recovery of each node in the supply network (Simchi-Levi et al., 2014). Intuitively, it might be appealing to say that the latter would be more effective for securing resilience because focus on recoverability might not depend on a preidentification of potential disruption events; however, our results do not support such a proposition, and indeed, the perspectives complement each other (Simchi-Levi et al., 2015).

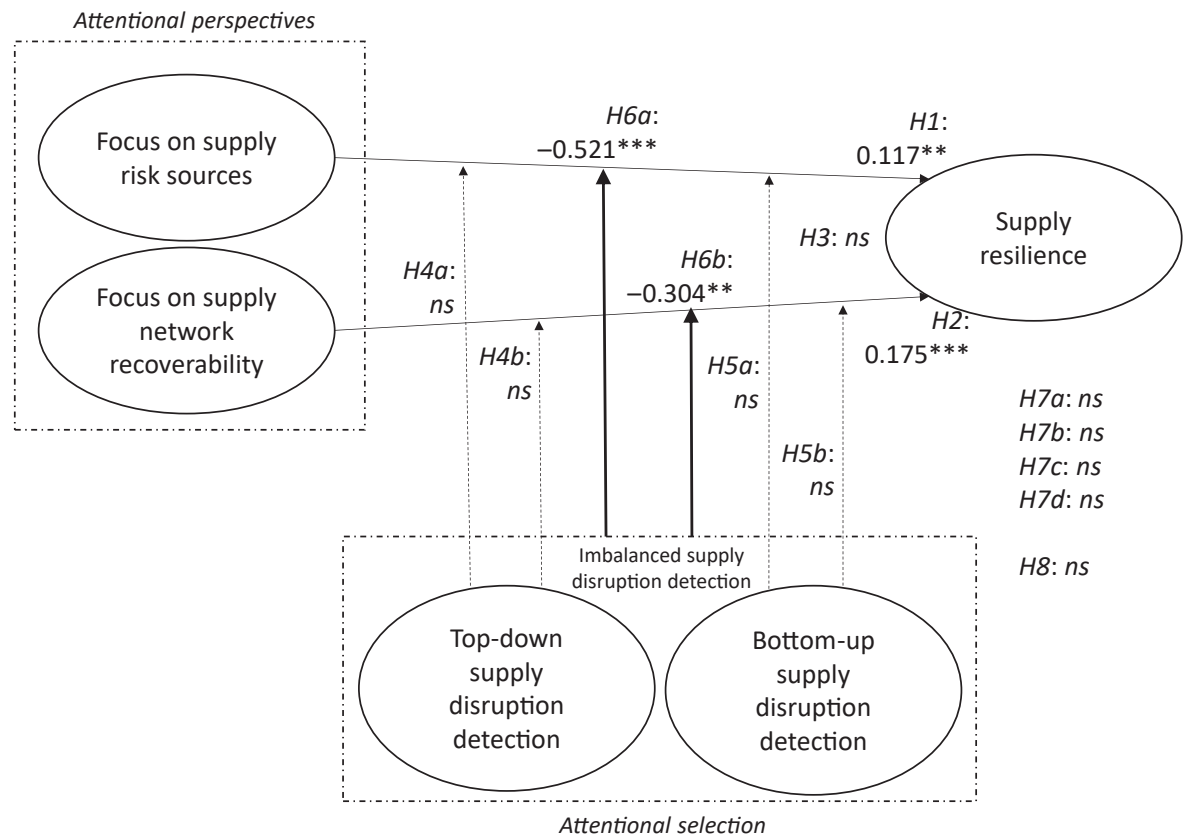

Note(s): $* * p<0.05, * * * p<0.01, n s:$ statistically not significant
Figure 2.

Research model and results 
The explanation for this lack of potency of the recoverability focus may lie in the practical difficulties of mapping and assessing complex multi-tier supply networks because of the sheer resource intensity of such a task (Fabbe-Costes et al., 2020; Choi and Hong, 2002). Because the potentially most effective approach may also be the most resource intensive (cf. Meinlschmidt et al., 2018), decision-makers may, unfortunately, resort to identifying and prioritising a list of risk sources and then paying attention to the potential disruption events and scenarios as risk sources. However, recent experiences regarding the procurement of critical healthcare supplies during the COVID-19 pandemic highlighted the negative effects of the limited knowledge of supply markets and networks on preparedness and resilience (Harland, 2021), emphasising the need for a complementary recoverability focus. The suggestion here is that the cost-benefit ratio of supply network mapping for recoverability may require re-evaluation, particularly because the cost of network mapping may be reduced in the future with new digital applications and resilience may indeed be an important competitive differentiator. Such efforts may benefit from building knowledge management systems to learn from past disruption events (Zsidisin et al., 2005).

Second, our data suggest the importance of managerial attention in the form of two types of attentional selection. Coexistence is important because reliance only on top-down or bottom-up supply disruption detection does not seem to be enough to produce favourable resilience outcomes. Therefore, our results support the idea of pursuing a balance in attentional selection, here aligned with the theory of organisational ambidexterity (Birkinshaw and Gupta, 2013) and the findings on attention in the procurement management context (Lorentz et al., 2019). Although our results are not able to capture the potential benefits of the dynamic balancing of top-down and bottom-up attentional selection over time, the contingencies for such capability-shifting processes may be addressed in future research (cf. Luger et al., 2018). The prolonged nature of disruptions related to the COVID-19 pandemic highlights the extreme conditions that require rethinking how supply networks are managed (Sodhi and Tang, 2021), possibly indicating the need to dynamically rebalance detection mechanisms throughout the life cycle of such extreme conditions.

Interestingly, our results did not support our hypothesis regarding the difference in terms of the degree of impact of the imbalance in supply disruption detection on the two attentional perspectives on supply disruption risk management. Based on our Assumption 2 that managers typically tend to be biased towards the top-down approach, we expected that the focus on sources would suffer more from imbalance. Descriptive statistics of our data proved our assumption wrong and showed that there is a group of managers with bottom-up bias, in addition to the group with top-down bias. Further research may seek to replicate our study and re-examine these associations for more conclusive results, as well as the contingencies that lead to bias towards the top-down or bottom-up attentional selection. We conclude that balancing attentional selection for disruption detection serves the purposes of both perspectives on supply disruption risk management.

Finally, the present study contributes to understanding the microfoundations of supply disruption risk management capability by focusing on the attention of supply managers (cf. Felin et al., 2012). Drawing parallels with the dynamic capability literature, for example, in terms of sensing as a recognition of opportunities (and threats), we show that attention indeed plays a microfoundational role as a building block of dynamic capabilities (Helfat and Peteraf, 2015). Our research provides insights into the microfoundational nature and role of attention in the context of supply disruption risk management.

\subsection{Managerial implications}

The results of the current study may encourage firms to purposefully develop their supply risk management practices. As demonstrated by a higher mean value, the predominant 
IJOPM

41,13

approach towards supply disruption risk management focuses on risk sources. Although the results do not show that either a focus on supply risk sources or on supply network recoverability is superior, the findings imply that both have a positive impact on supply resilience; thus, both should be implemented (Simchi-Levi et al., 2015). Because there might be resource constraints when focusing on recoverability, firms may consider collaborative risk management across supply chains as a solution (Azadegan and Dooley, 2021), thus remedying the bias towards a focus on risk sources.

Given the tendency for imbalance in attentional selection for disruption detection, managers must consider interventions for balancing. For example, when there is a need to emphasise bottom-up attentional selection more, such as when organisations may face equivocality and discontinuous change in supply markets, firms should use supply market intelligence acquisition mechanisms that facilitate the collecting and processing of rich information. These may include, for example, direct discussions and meetings with suppliers and internal stakeholders, the maintenance of personal contact networks and the deployment of news feeds or collaborative platforms (Lorentz et al., 2020).

Finally, can the lessons learned during the COVID-19 pandemic be applied to other potential disruptions? Sarkis (2020) notes that the pandemic was not an unexpected black swan because there were warnings and knowledge available beforehand. They point out that climate shocks, such as droughts, floods, fires and loss of biodiversity, intensified by global warming are going to be a similar test for the resilience and preparedness of supply chains, yet how managers focus attention on these remains under-researched. Identifying the current weaknesses in risk management from an attentional point of view may help organisations design the processes and structures that will ensure their survival during prolonged global disruptions.

\subsection{Limitations and future research}

Our study is subject to some limitations that may offer opportunities for further research. Our data were collected from developed European countries in the COVID-19 context, which may limit the generalisability of the findings to other geographies and disruption contexts. The majority of the respondents represented manufacturing firms. Diversifying the range of countries and industries with different socioeconomic contexts would allow for a comparative understanding of the role of different organisational and cultural contexts in COVID-19 supply chain issues (Chowdhury et al., 2021). In addition, the data collection was crosssectional, which should be considered when drawing conclusions regarding the causality of the studied constructs.

The data were collected in the spring and summer of 2020 when the global COVID-19 outbreak was still in its relatively early stages. It is likely that the firms surveyed were most severely affected by the first wave of the pandemic. Since then, many firms have been forced to alter their practices. Future research can hopefully demonstrate the long-term impacts of the changes imposed by COVID-19. It will be interesting to see if the focus of supply disruption risk management will shift towards supply network and recoverability when firms have come to realise that it may be impossible to prespecify all risk sources and events and preassess their impacts. Because supply network recoverability as a risk management approach may be more challenging to execute because of its resource intensity, future research may suggest ways to improve network recoverability.

Given that there may be naturally occurring tendencies towards imbalance in the attentional selection for disruption detection, a qualitative deep dive into how firms can adjust and (re)balance would be a promising research topic. In particular, there is a need to study resilience and supply risk management at a micro level, that is, at the level of an individual decision maker (Mena et al., 2020). For example, an ethnographic study could 
uncover how the attentional processing of individual procurement professionals determines the realised supply disruption risk management approach, along with how these processes may be collectively managed. Finally, there are a number of supply network variables that may have an effect on the biases towards either of the perspectives on supply disruption risk management or the attentional selection for disruption detection. Future research may, for example, control for supply network complexity, as well as the nature of supplier relationships, to understand the effects of such contingencies on these biases and imbalances.

Attention and supply disruption risk management

\section{References}

Abadie, L.M., Galarraga, I. and Murieta, E.S.D. (2017), "Understanding risks in the light of uncertainty. Low-probability, high-impact coastal events in cities”, Environmental Research Letters, Vol. 12 No. 1, p. 14017.

Akkermans, H. and Van Wassenhove, L.N. (2018a), "Supply chain tsunamis: research on lowprobability, high-impact disruptions", Journal of Supply Chain Management, Vol. 54 No. 1, pp. 64-76.

Akkermans, H.A. and Van Wassenhove, L.N. (2018b), "A dynamic model of managerial response to grey swan events in supply networks", International Journal of Production Research, Vol. 56 Nos 1-2, pp. 10-21.

Ambulkar, S., Blackhurst, J. and Grawe, S. (2015), "Firm's resilience to supply chain disruptions: scale development and empirical examination", Journal of Operations Management, Vol. 33, pp. 111-122.

Anderson, J.C. and Gerbing, D.W. (1988), "Structural equation modeling in practice: a review and recommended two-step approach", Psychological Bulletin, Vol. 103 No. 3, p. 411.

Armstrong, J.S. and Overton, T.S. (1977), "Estimating nonresponse bias in mail surveys", Journal of Marketing Research, Vol. 14 No. 3, pp. 396-402.

Azadegan, A. and Dooley, K. (2021), “A typology of supply network resilience strategies: complex collaborations in a complex world", Journal of Supply Chain Management, Vol. 57 No. 1, pp. 17-26.

Banker, S. (2020), "A very agile supply chain: the inside story of AGCO's response to COVID-19", Supply Chain Management Review, available at: https://www.scmr.com/article/a_very_agile_ supply_chain_the_inside_story_of_agcos_response_to_covid_19 (accessed 25 October 2021).

Barney, J.A.Y. and Felin, T. (2013), "What are microfoundations?", Academy of Management Perspectives, Vol. 27 No. 2, pp. 138-155.

Birkinshaw, J. and Gupta, K. (2013), "Clarifying the distinctive contribution of ambidexterity to the field of organization studies", Academy of Management Perspectives, Vol. 27 No. 4, pp. 287-298.

Blackhurst, J., Dunn, K.S. and Craighead, C.W. (2011), "An empirically derived framework of global supply resiliency”, Journal of Business Logistics, Vol. 32 No. 4, pp. 374-391.

Bode, C. and Wagner, S.M. (2015), "Structural drivers of upstream supply chain complexity and the frequency of supply chain disruptions", Journal of Operations Management, Vol. 36, pp. 215-228.

Bode, C. and Macdonald, J.R. (2016), "Stages of supply chain disruption response: direct, constraining, and mediating factors for impact mitigation", Decision Sciences, Vol. 48 No. 5, pp. 836-874.

Braunscheidel, M.J. and Suresh, N.C. (2009), "The organizational antecedents of a firm's supply chain agility for risk mitigation and response", Journal of Operations Management, Vol. 27 No. 2, pp. 119-140.

Busse, C., Kach, A.P. and Wagner, S.M. (2017), "Boundary conditions: what they are, how to explore them, why we need them, and when to consider them", Organizational Research Methods, Vol. 20 No. 4, pp. 574-609. 
IJOPM

41,13

Butt, A.S. (2021), "Strategies to mitigate the impact of COVID-19 on supply chain disruptions: a multiple case analysis of buyers and distributors", The International Journal of Logistics Management, Vol. ahead-of-print No. ahead-of-print. doi: 10.1108/IJLM-11-2020-0455.

Chaudhuri, A., Ghadge, A., Gaudenzi, B. and Dani, S. (2020), "A conceptual framework for improving effectiveness of risk management in supply networks", The International Journal of Logistics Management, Vol. 31 No. 1, pp. 77-98.

Cho, T.S. and Hambrick, D.C. (2006), "Attention as the mediator between top management team characteristics and strategic change: the case of airline deregulation", Organization Science, Vol. 17 No. 4, pp. 453-469.

Choi, T.Y. and Hong, Y. (2002), "Unveiling the structure of supply networks: case studies in Honda, Acura, and DaimlerChrysler", Journal of Operations Management, Vol. 20 No. 5, pp. 469-493.

Choi, T.Y., Rogers, D. and Vakil, B. (2020), "Coronavirus is a wake-up call for supply chain management", Harvard Business Review, March, pp. 364-398.

Chowdhury, P., Paul, S.K., Kaisar, S. and Moktadir, M.A. (2021), "COVID-19 pandemic related supply chain studies: a systematic review", Transportation Research Part E: Logistics and Transportation Review, Vol. 148, 102271.

Craighead, C.W., Blackhurst, J., Rungtusanatham, M.J. and Handfield, R.B. (2007), "The severity of supply chain disruptions: design characteristics and mitigation capabilities", Decision Sciences, Vol. 38 No. 1, pp. 131-156.

Curran, P.J., West, S.G. and Finch, J.F. (1996), "The robustness of test statistics to nonnormality and specification error in confirmatory factor analysis”, Psychological Methods, Vol. 1 No. 1, p. 16.

Cyert, R.M. and March, J.G. (1963), A Behavioral Theory of the Firm, Prentice Hall, Englewood Cliffs, NJ.

Day, G.S. and Schoemaker, P.J. (2004), "Driving through the fog: managing at the edge", Long Range Planning, Vol. 37 No. 2, pp. 127-142.

Ellis, S.C., Henry, R.M. and Shockley, J. (2010), "Buyer perceptions of supply disruption risk: a behavioral view and empirical assessment”, Journal of Operations Management, Vol. 28 No. 1, pp. 34-46.

Fabbe-Costes, N., Lechaptois, L. and Spring, M. (2020), “The map is not the territory': a boundary objects perspective on supply chain mapping", International Journal of Operations and Production Management, Vol. 40 No. 9, pp. 1475-1497.

Fan, H., Cheng, T.C.E., Li, G. and Lee, P.K. (2016), "The effectiveness of supply chain risk information processing capability: an information processing perspective", IEEE Transactions on Engineering Management, Vol. 63 No. 4, pp. 414-425.

Felin, T., Foss, N.J., Heimeriks, K.H. and Madsen, T.L. (2012), "Microfoundations of routines and capabilities: individuals, processes, and structure", Journal of Management Studies, Vol. 49 No. 8, pp. 1351-1374.

Flynn, B., Pagell, M. and Fugate, B. (2018), "Editorial: survey research design in supply chain management: the need for evolution in our expectations", Journal of Supply Chain Management, Vol. 54 No. 1, pp. 1-15.

Fornell, C. and Larcker, D.F. (1981), "Evaluating structural equation models with unobservable variables and measurement error”, Journal of Marketing Research, Vol. 18 No. 1, pp. 39-50.

Friday, D., Ryan, S., Sridharan, R. and Collins, D. (2018), "Collaborative risk management: a systematic literature review", International Journal of Physical Distribution and Logistics Management, Vol. 48 No. 3, pp. 231-253.

Fuller, C.M., Simmering, M.J., Atinc, G., Atinc, Y. and Babin, B.J. (2016), "Common methods variance detection in business research", Journal of Business Research, Vol. 69 No. 8, pp. 3192-3198.

Garver, M.S. and Mentzer, J.T. (1999), "Logistics research methods: employing structural equation modeling to test for construct validity", Journal of Business Logistics, Vol. 20 No. 1, p. 33. 
Habermann, M., Blackhurst, J. and Metcalf, A.Y. (2015), "Keep your friends close? Supply chain design and disruption risk", Decision Sciences, Vol. 46 No. 3, pp. 491-526.

Hair, J.F. Jr, Black, W.C., Babin, B.J. and Anderson, R.E. (2010), Multivariate Data Analysis, 7th ed., Pearson Prentice Hall, Upper Saddle River, NJ.

Harland, C. (2021), "Discontinuous wefts: weaving a more interconnected supply chain management tapestry", Journal of Supply Chain Management, Vol. 57 No. 1, pp. 27-40.

Heckmann, I., Comes, T. and Nickel, S. (2015), "A critical review on supply chain risk - definition, measure and modeling”, Omega, Vol. 52, pp. 119-132.

Helfat, C.E. and Peteraf, M.A. (2015), "Managerial cognitive capabilities and the microfoundations of dynamic capabilities", Strategic Management Journal, Vol. 36 No. 6, pp. 831-850.

Henseler, J., Ringle, C.M. and Sarstedt, M. (2015), "A new criterion for assessing discriminant validity in variance-based structural equation modeling", Journal of the Academy of Marketing Science, Vol. 43 No. 1, pp. 115-135.

Hodgson, G.M. (2007), "Meanings of methodological individualism”, Journal of Economic Methodology, Vol. 14 No. 2, pp. 211-226.

Hu, L.T. and Bentler, P.M. (1999), "Cutoff criteria for fit indexes in covariance structure analysis: conventional criteria versus new alternatives", Structural Equation Modeling: A Multidisciplinary Journal, Vol. 6 No. 1, pp. 1-55.

Ivanov, D. and Dolgui, A. (2019), "Low-Certainty-Need (LCN) supply chains: a new perspective in managing disruption risks and resilience", International Journal of Production Research, Vol. 57 Nos 15-16, pp. 5119-5136.

Ivanov, D. and Das, A. (2020), "Coronavirus (COVID-19/SARS-CoV-2) and supply chain resilience: a research note", International Journal of Integrated Supply Management, Vol. 13 No. 1, pp. 90-102.

Junni, P., Sarala, R.M., Taras, V.A.S. and Tarba, S.Y. (2013), "Organizational ambidexterity and performance: a meta-analysis”, Academy of Management Perspectives, Vol. 27 No. 4, pp. 299-312.

Kauppi, K., Longoni, A., Caniato, F. and Kuula, M. (2016), "Managing country disruption risks and improving operational performance: risk management along integrated supply chains", International Journal of Production Economics, Vol. 182, pp. 484-495.

Kim, Y., Chen, Y.S. and Linderman, K. (2015), "Supply network disruption and resilience: a network structural perspective", Journal of Operations Management, Vol. 33, pp. 43-59.

Kleindorfer, P.R. and Saad, G.H. (2005), "Managing disruption risks in supply chains", Production and Operations Management, Vol. 14 No. 1, pp. 53-68.

Krause, D., Luzzini, D. and Lawson, B. (2018), "Building the case for a single key informant in supply chain management survey research", Journal of Supply Chain Management, Vol. 54 No. 1, pp. $42-50$.

Lavie, D., Stettner, U. and Tushman, M.L. (2010), "Exploration and exploitation within and across organizations", Academy of Management Annals, Vol. 4 No. 1, pp. 109-155.

Lindell, M.K. and Whitney, D.J. (2001), "Accounting for common method variance in cross-sectional research designs", Journal of Applied Psychology, Vol. 86 No. 1, p. 114.

Linton, T. and Vakil, B. (2020), "Coronavirus is proving we need more resilient supply chains", Harvard Business Review, March, available at: https:/hbr.org/2020/03/coronavirus-is-provingthat-we-need-more-resilient-supply-chains (accessed 25 October 2021).

Lorentz, H., Töyli, J., Solakivi, T. and Ojala, L. (2016), "The effect of a geographically dispersed supply base on downside risk: developing and testing the N-shaped theory", International Business Review, Vol. 25 No. 4, pp. 872-882.

Lorentz, H., Laari, S., Engblom, J. and Tanskanen, K. (2019), "Attention-based view on achieving ambidexterity in purchasing and supply management", Journal of Purchasing and Supply Management, Vol. 25 No. 5, p. 100560.
Attention and supply disruption risk management 
IJOPM

41,13

Lorentz, H., Aminoff, A., Kaipia, R., Pihlajamaa, M., Ehtamo, J. and Tanskanen, K. (2020), “Acquisition of supply market intelligence-An information processing perspective", Journal of Purchasing and Supply Management, Vol. 26 No. 5, p. 100649.

Lu, G., Ding, X., Peng, D.X. and Chuang, H.H. (2018), “Addressing endogeneity in operations management research: recent developments, common problems, and directions for future research", Journal of Operations Management, Vol. 64, pp. 53-64.

Luger, J., Raisch, S. and Schimmer, M. (2018), "Dynamic balancing of exploration and exploitation: the contingent benefits of ambidexterity", Organization Science, Vol. 29 No. 3, pp. 449-470.

MacCallum, R.C., Browne, M.W. and Sugawara, H.M. (1996), "Power analysis and determination of sample size for covariance structure modeling”, Psychological Methods, Vol. 1 No. 2, p. 130.

Meinlschmidt, J., Schleper, M.C. and Foerstl, K. (2018), "Tackling the sustainability iceberg", International Journal of Operations and Production Management, Vol. 38 No. 10, pp. 1888-1914.

Mena, C., Melnyk, S.A., Baghersad, M. and Zobel, C.W. (2020), "Sourcing decisions under conditions of risk and resilience: a behavioral study”, Decision Sciences, Vol. 51 No. 4, pp. 985-1014.

Montabon, F., Daugherty, P.J. and Chen, H. (2018), "Setting standards for single respondent survey design”, Journal of Supply Chain Management, Vol. 54 No. 1, pp. 35-41.

Norrman, A. and Jansson, U. (2004), "Ericsson's proactive supply chain risk management approach after a serious sub-supplier accident”, International Journal of Physical Distribution and Logistics Management, Vol. 34 No. 5, pp. 434-456.

Ocasio, W. (1997), "Towards an attention-based view of the firm”, Strategic Management Journal, Vol. 18 No. S1, pp. 187-206.

Ocasio, W. (2011), “Attention to attention”, Organization Science, Vol. 22 No. 5, pp. 1286-1296.

Pettit, T.J., Fiksel, J. and Croxton, K.L. (2010), "Ensuring supply chain resilience: development and implementation of an assessment tool”, Journal of Business Logistics, Vol. 34 No. 1, pp. 46-76.

Podsakoff, P.M., MacKenzie, S.B., Lee, J.Y. and Podsakoff, N.P. (2003), "Common method biases in behavioral research: a critical review of the literature and recommended remedies", Journal of Applied Psychology, Vol. 88 No. 5, p. 879.

Revilla, E. and Saenz, M.J. (2017), "The impact of risk management on the frequency of supply chain disruptions", International Journal of Operations and Production Management, Vol. 37 No. 5, pp. 557-576.

Riley, J.M., Klein, R., Miller, J. and Sridharan, V. (2016), "How internal integration, information sharing, and training affect supply chain risk management capabilities", International Journal of Physical Distribution and Logistics Management, Vol. 46 No. 10, pp. 953-980.

Rungtusanatham, M., Forza, C., Koka, B.R., Salvador, F. and Nie, W. (2005), "TQM across multiple countries: convergence hypothesis versus national specificity arguments", Journal of Operations Management, Vol. 23 No. 1, pp. 43-63.

Sarkis, J. (2020), "Supply chain sustainability: learning from the COVID-19 pandemic", International Journal of Operations and Production Management, Vol. 41 No. 1, pp. 63-73.

Schulz-Hardt, S., Frey, D., Lüthgens, C. and Moscovici, S. (2000), "Biased information search in group decision making", Journal of Personality and Social Psychology, Vol. 78 No. 4, p. 655.

Shao, X.F. (2013), "Supply chain characteristics and disruption mitigation capability: an empirical investigation in China", International Journal of Logistics Research and Applications, Vol. 16 No. 4, pp. 277-295.

Sheffi, Y. (2005), The Resilient Enterprise: Overcoming Vulnerability for Competitive Advantage, The MIT Press, Cambridge, MA.

Shepherd, D.A., Mcmullen, J.S. and Ocasio, W. (2017), "Is that an opportunity? An attention model of top managers' opportunity beliefs for strategic action”, Strategic Management Journal, Vol. 38 No. 3, pp. 626-644. 
Simchi-Levi, D., Schmidt, W. and Wei, Y. (2014), "From superstorms to factory fires: managing unpredictable supply chain disruptions", Harvard Business Review, Vol. 92 Nos 1-2, pp. 96-101.

Simchi-Levi, D., Schmidt, W., Wei, Y., Zhang, P.Y., Combs, K., Ge, Y., Gusikhin, O., Sanders, M. and Zhang, D. (2015), "Identifying risks and mitigating disruptions in the automotive supply chain", Interfaces, Vol. 45 No. 5, pp. 375-390.

Simchi-Levi, D., Wang, H. and Wei, Y. (2018), "Increasing supply chain robustness through process flexibility and inventory", Production and Operations Management, Vol. 27 No. 8, pp. 1476-1491.

Simon, H.A. (1947), "A comment on "the science of public administration", Public Administration

Attention and supply disruption risk management

Sodhi, M.S. and Tang, C.S. (2021), "Supply chain management for extreme conditions: research opportunities", Journal of Supply Chain Management, Vol. 57 No. 1, pp. 7-16.

Son, B.-G., Chae, S. and Kocabasoglu-Hillmer, C. (2021), "Catastrophic supply chain disruptions and supply network changes: a study of the 2011 Japanese earthquake", International Journal of Operations and Production Management, Vol. 41 No. 6, pp. 781-804.

Voorhees, C.M., Brady, M.K., Calantone, R. and Ramirez, E. (2016), "Discriminant validity testing in marketing: an analysis, causes for concern, and proposed remedies", Journal of the Academy of Marketing Science, Vol. 44 No. 1, pp. 119-134.

Walsh, J.P. (1995), "Managerial and organizational cognition: notes from a trip down memory lane", Organization Science, Vol. 6 No. 3, pp. 280-321.

Wieland, A. and Durach, C.F. (2021), "Two perspectives on supply chain resilience", Journal of Business Logistics, pp. 315-322, doi: 10.1111/jbl.12271.

Wiengarten, F. and Pagell, M. (2012), "The importance of quality management for the success of environmental management initiatives", International Journal of Production Economics, Vol. 140 No. 1, pp. 407-415.

Wiengarten, F., Pagell, M. and Fynes, B. (2012), "Supply chain environmental investments in dynamic industries: comparing investment and performance differences with static industries", International Journal of Production Economics, Vol. 135 No. 2, pp. 541-551.

Williams, L.J., Hartman, N. and Cavazotte, F. (2010), "Method variance and marker variables: a review and comprehensive CFA marker technique", Organizational Research Methods, Vol. 13 No. 3, pp. 477-514.

Wouters, M., Anderson, J.C. and Wynstra, F. (2005), "The adoption of total cost of ownership for sourcing decisions. A structural equations analysis", Accounting, Organizations and Society, Vol. 30 No. 2, pp. 167-191.

Yan, T., Choi, T.Y., Kim, Y. and Yang, Y. (2015), "A theory of the nexus supplier: a critical supplier from a network perspective", Journal of Supply Chain Management, Vol. 51 No. 1, pp. 52-66.

Zellner, A. (1962), "An efficient method of estimating seemingly unrelated regressions and tests for aggregation bias", Journal of the American Statistical Association, Vol. 57 No. 298, pp. 348-368.

Zsidisin, G.A. and Wagner, S.M. (2010), "Do perceptions become reality? The moderating role of supply chain resiliency on disruption occurrence", Journal of Business Logistics, Vol. 31 No. 2, pp. 1-20.

Zsidisin, G.A., Melnyk, S.A. and Ragatz, G.L. (2005), "An institutional theory perspective of business continuity planning for purchasing and supply management", International Journal of Production Research, Vol. 43 No. 16, pp. 3401-3420. 
IJOPM

41,13

\section{Appendix}

Mean

SD

Focus on supply risk sources (novel, drawing on Kleindorfer and Saad, 2005 and Fan et al., 2016)

During the past year in my area of procurement responsibility (e.g. a spend category or an item) ...

... There has been an effort to regularly pre-specify possible risks and disruptions

... There has been an effort to regularly pre-assess the probability of possible disruptions

$4.64 \quad 1.586$

... There has been an effort to regularly pre-assess the impact of possible disruptions

$4.68 \quad 1.521$

... Supply risks have been managed by pre-identifying and pre-assessing possible

$4.89 \quad 1.464$ disruptions

Focus on supply network recoverability (novel, drawing on Simchi-Levi et al., 2014)

During the past year in my area of procurement responsibility (e.g. a spend category or an item) ...

... There has been an effort to map our multi-tier supply network to assess its ability to

recover from disruptions

... There has been an effort to regularly survey our suppliers' ability to recover from disruptions

... There has been an effort to regularly survey our multi-tier supplier network's ability to recover from disruptions

... There has been an effort to assess our suppliers' time-to-recovery from disruptions

$3.49 \quad 1.672$

... There has been an effort to shorten our supply network's time-to-recovery from disruptions

Top-down supply disruption detection (novel, drawing on Shepherd et al., 2017 and Lorentz et al., 2019) During the past year in my area of procurement responsibility (e.g. a spend category or an item) ... .

... Known supplier network vulnerabilities have been used to focus the scanning for possible supply disruptions

... Existing risk analyses have been used to focus the scanning for possible supply disruptions

... Accumulated experience has been beneficial in efficient scanning for possible supply disruptions

... A limited set of reports and news focused on identified risks have been used to concentrate the scan for possible supply disruptions

Bottom-up supply disruption detection (novel, drawing on Shepherd et al., 2017 and Lorentz et al., 2019) During the past year in my area of procurement responsibility (e.g. a spend category or an item) ... .

... There has been open discussion with suppliers in order to detect unanticipated disruptions

... There has been open discussion with other functions of our company (e.g. R\&D) in order to detect unanticipated disruptions

... There has been a regular follow-up of current phenomena in order to detect unanticipated disruptions

... There has been utilisation of teams or expert networks for detecting unanticipated disruptions

Supply resilience (adapted from Ambulkar et al. 2015)

During the COVID-19 pandemic in my area of procurement responsibility (e.g. a spend category or an item) ... 


\begin{tabular}{|c|c|c|}
\hline & Mean & $\mathrm{SD}$ \\
\hline We have been able to cope with changes brought by supply disruptions & 5.83 & 1.167 \\
\hline We have been able to adapt to supply disruptions easily & 5.29 & 1.335 \\
\hline We have been able to provide a quick response to supply disruptions & 5.63 & 1.295 \\
\hline $\begin{array}{l}\text {... We have been able to maintain high situational awareness at all times during supply } \\
\text { disruptions }\end{array}$ & 5.57 & 1.368 \\
\hline Control variables & & \\
\hline $\begin{array}{l}\text { Please assess the impact of the COVID-19 pandemic on the supply chain/supplier network of } \\
\text { your category or item }\end{array}$ & 3.52 & 1.304 \\
\hline $\begin{array}{l}\text { Turnover: 1) 0-2 million EUR, 2) 2.1-10 million EUR, 3) 10.1-50 million EUR, and 4) over } 50 \\
\text { million EUR }\end{array}$ & 2.98 & - \\
\hline
\end{tabular}

Attention and disruption risk management

\section{Corresponding author}

Harri Lorentz can be contacted at: harri.lorentz@utu.fi

For instructions on how to order reprints of this article, please visit our website:

www.emeraldgrouppublishing.com/licensing/reprints.htm

Or contact us for further details: permissions@emeraldinsight.com 